This item was submitted to Loughborough's Research Repository by the author.

Items in Figshare are protected by copyright, with all rights reserved, unless otherwise indicated.

\title{
Water utility consultation with the urban poor in developing countries
}

PLEASE CITE THE PUBLISHED VERSION

http://www.municipalengineer.com

\section{PUBLISHER}

(c) Institution of Civil Engineers

VERSION

VoR (Version of Record)

LICENCE

CC BY-NC-ND 4.0

\section{REPOSITORY RECORD}

Coates, Sue, Kevin Sansom, and J. Colin. 2019. "Water Utility Consultation with the Urban Poor in Developing Countries". figshare. https://hdl.handle.net/2134/9813. 
This item was submitted to Loughborough's Institutional Repository (https://dspace.lboro.ac.uk/) by the author and is made available under the following Creative Commons Licence conditions.

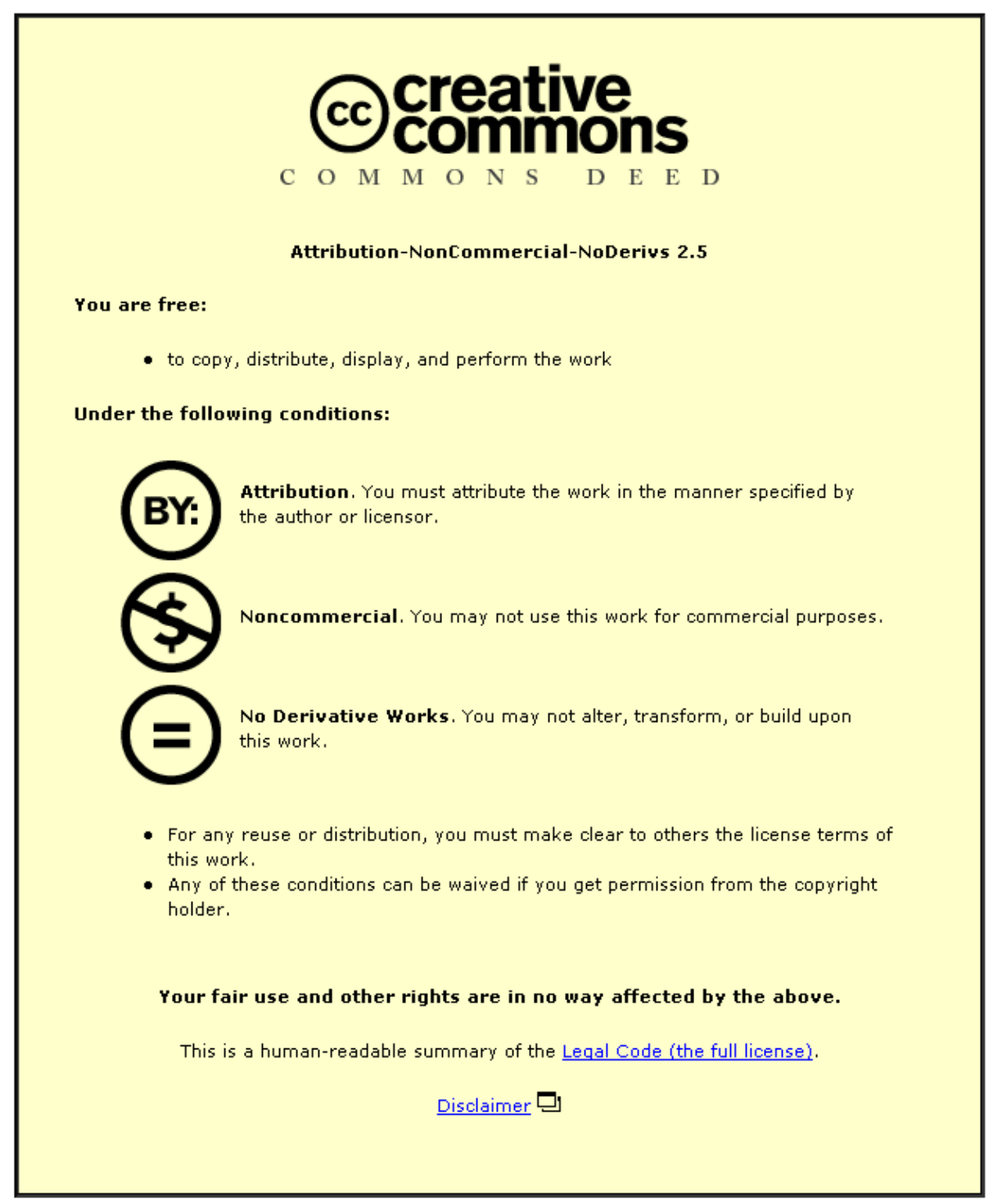

For the full text of this licence, please go to: http://creativecommons.org/licenses/by-nc-nd/2.5/ 


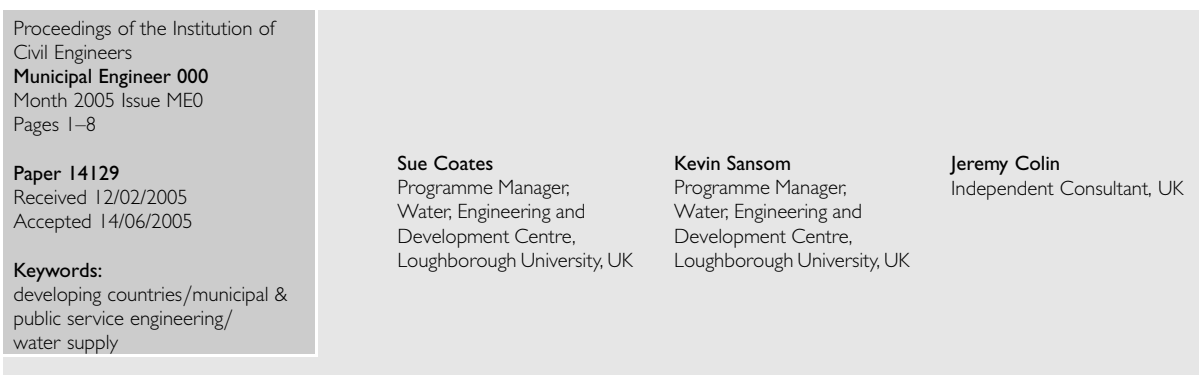

\section{Water utility consultation in developing countries}

S. Coates MSc, K. Sansom MSc, CEng, MICE and J. Colin MSc

Inadequate water services to the urban poor remain a serious problem in developing countries. Where services do exist, the chosen engineering solution often proves unsustainable. Engineers relying heavily on technical expertise can fail to understand the contextual factors determining what poor people want and are willing to pay. Although the concept of appropriate technology options is common enough, technology alone cannot provide a sustainable service. Tariffs and management options must also be designed to meet the needs of the poor. 'PREPP (participation-ranking-experience-perceptionpartnership)', is a consumer consultation process for use by engineers with the support of social scientists and community development workers. These professionals traditionally see service provision from diverse perspectives and in developing countries they rarely work as a team. Through PREPP, engineers are able to understand the problems of service provision in poor urban settings through the eyes of poor consumers and the professionals that more commonly work with them. Likewise, social sciences professionals are better able to understand engineering parameters. The result is a cost-effective and relatively rapid process that helps engineers to design relevant engineering solutions with more chance of sustainability. Experience in Zambia, India, Kenya and Uganda is illustrated.

\section{INTRODUCTION}

Inadequate water services to the urban poor remain a serious challenge for utilities and municipalities in developing countries. Although successful innovations exist, experience shows that engineers rely too heavily on technical expertise and assumed levels of demand for services, failing to understand the contextual issues determining what poor people want and are willing to pay. Engineers' education, especially in academic institutions where didactic teaching prevails, does not develop the essential communication and consultation skills required to engage with the cultural, social and economic factors that impact upon poor consumers. Inadequate choices of water supply technology, tariff, payment and management options result. This paper looks at these areas of concern and introduces PREPP (participation-ranking-experience-perception-partnership)-a multi-disciplinary consumer consultation process designed to enable utilities to address these deficiencies.

\section{THE PROBLEM OF WATER SUPPLY FOR THE URBAN POOR}

One third of the world's urban households live in extreme poverty, existing on less than a dollar a day. Many of them reside in unplanned settlements that lack basic infrastructure and services. To achieve the Millennium Development Goal drinking water and sanitation target, some one billion more people need to be provided with basic sanitation services alone. ${ }^{1}$ Despite recognition by governments of the problems, the provision of 24-hour water supply, seven days a week to whole populations is simply out of reach. Given that resources are finite it is more realistic to think in terms of providing 'some for all' rather than 'all for some'.

Achievement of a more equitable situation requires a radical change from established arrangements whereby middle- and high-income households receive relatively generous supplies paying low tariffs, while poorer communities are grossly underserved. This is a huge challenge especially given that:

- poor urban settlements are often densely populated, irregular in layout and located far from main supply lines, causing difficulty and expense when installing conventional water supply networks;

- many poor households are unable to pay standard connection charges for a household tap;

- the contextual issues (social, economic, cultural) that determine what poor people want and are willing to pay are complex; and

- utilities are often reluctant to extend services to poor communities, especially when high capital costs are set against the perception of poor revenue generation from standard service options such as public stand posts.

The task is urgent but requires more than the laying of pipes. New and innovative ways of communicating with consumers; the development of new service options; skilled organisational management; strategic business planning; and the development of creative partnerships between government, the private sector and civil society are required.

\section{MAKING CHANGES}

Public utilities are casualties of years of government inertia as well as the day-to-day uncertainties of a highly complicated political, technical, economic and socio-cultural environment. 
It is not surprising that achieving change in such institutions is difficult. New Public Management, ${ }^{2}$ seeing government as facilitator (which might include contract management and regulation) rather than the traditional provider of services, is the current paradigm advocated to better ensure the sustainability of infrastructure. But herein lies the problem: how to shift the "we are the champions of infrastructure' mindset of many engineers to one that sees the role as a 'facilitator of sustainable services'. Somehow the best of engineering practice has to meet the best of social sciences practice and economic common sense.

Governments and donors are increasingly more poverty focused in the design of infrastructure, advocating a demand responsive approach. In urban water supply this involves improving services to informal settlements where 30 to $70 \%$ of city dwellers live in developing countries. Most of these people are not direct customers of water utilities and have to endure long queues at water kiosks or pay high prices for small quantities from water vendors. The key challenge is how to provide much better services in these settlements in a financially sustainable manner.

Traditionally the only piped water service options on offer were in-house connections and public stand posts or water kiosks. Innovative ways of serving the poor are emerging to include a range of options. For example in South Africa, the utility Durban Metro Water has the following 'menu' of service options:

- water kiosks (with or without storage) where people collect water and pay per 20 litre container;

- individual house connections with a 200 litre ground tank in the yard, trickle fed;

- individual house connections with limited pressure using roof tanks;

- individual house connections with full pressure (conventional 24-hour supply). ${ }^{3}$

In informal settlements in Buenos Aires the utility Aguas Argentinas has also identified the need for a range of service options to suit demand; no single option suits all. Participative Water Service projects link residents with the utility via a Community Based Organisation or Non-Government Organisation. The utility designs the projects and supervises implementation, with the community providing labour to minimise costs. ${ }^{3}$

\section{PROFESSIONAL IDENTITY AND THE NEED FOR MULTI-DISCIPLINARY TEAMS}

Engineers have an excellent foundation in dealing with technical design, with the management of physical resources, with budgets and construction management. However, some graduate and professional engineering education often neglects developing engineers' ability with less tangible concepts. For example, sustainability, poverty, gender and inter-disciplinary approaches are diffuse subjects and engineers' ability to deal with them still requires improvement. The common response is to constrain these 'softer' issues through out-sourcing and the separating out of job descriptions. For example, gender experts and sociologists rather than engineering experts often deal with the 'gender' aspects of a project. This invariably leads to a tokenism rather than reducing the burden on women (the main collectors of water) through their involvement in the design of 'acceptableto-female-user' water facilities. ${ }^{4}$

The answer is not to make engineers into sociologists and vice versa. More practical is the adoption of holistic team approaches to the design and delivery of services for the urban poor, bringing disciplines and professions together with end users; a simple enough idea but one that confronts the very heart of professional chauvinism and job demarcation.

One 'doable' way forward is the implementation of 'PREPP'. This participatory consumer consultation process, led by engineers and developed by practitioner researchers (local engineers, social scientists and economists) acknowledges a most basic flaw: that these professionals traditionally approach the provision of services to the poor from diverse perspectives and in developing countries rarely work as a team. Hence their strengths are not maximised to develop sustainable outcomes and learning remains compartmentalised. PREPP focuses on collaboration for skill development and the achievement of outcomes through multi-disciplinary teamwork. This enables engineers to understand the urban poor and social scientists to appreciate engineering constraints. The PREPP approach, field tested in Africa and Asia is a cost-effective and relatively rapid process that helps engineers, and so utilities, to rethink their methods for determining service provision. PREPP is built upon a blend of existing commercial marketing and community development principles.

\section{PERSPECTIVES, BASIC PRINCIPLES AND KNOWING WHO KNOWS WHAT}

Understanding perspectives and achieving 'likeminded-ness' about some basic principles is the foundation of sustainable teamwork. Above all is acknowledgment that, “I know everything” built a house without a door"* or, in this case "they who design the water system invariably fail to meet the demand of its users'.

In utility environments where communication is strictly hierarchical and the recruitment of non-engineering personnel to operational and management positions is still rare, perspectives can be ingrained and remain unchallenged. Likewise in social science based organisations polarised views of supply-driven engineers can be unhelpful. There is now broad consensus that the design and delivery of water supply and sanitation services should be informed by, and responsive to, user demand. This is evidenced by countless examples of schemes falling rapidly into obsolescence because they fail to meet users' needs effectively, are unaffordable to users, and/or are poorly operated and maintained. Basically projects based on assumed demand estimates by engineers, as part of the old 'predict and provide' approach have often failed.

However, the assessment of demand can be problematic, especially when people express their needs in very general terms and different professionals interpret 'demand' variously. Engineers, for example, tend to treat demand as a quantitative term based on a standard figure for litres per capita per day relating to the supply of water, while for social development professionals and community representatives it concerns the

*Zambian proverb. 
realisation of basic rights. For our purposes, demand means 'an informed expression of desire for a particular service, assessed by the investments people are prepared to make, over the lifetime of the service, to receive it and sustain it'. ${ }^{5}$

This definition is essentially an economic one (people have to be willing to pay) but it has implications for technical design and service management if the vicious circle of failing schemes is to become virtuous. A simple statement such as 'we want more water' does not reveal anything as to the service or payment options that people would prefer. In order to meet demand effectively, service providers need to enter into a meaningful dialogue with users, thus enabling both parties to make informed choices.

Successful companies know that customer orientation is essential for commercial success. Satisfied customers who have confidence in their service provider are more likely to pay than those who are dissatisfied-an important consideration in the water sector where revenue generation is problematic and mistrust of public water supply agencies common. Jointly, engineers and sociologists can get to grips with what the urban poor want and are willing to pay.

\section{MARKETING}

Marketing is a valid tool for identifying, anticipating and satisfying consumer demand ${ }^{6}$ in a cost-efficient manner. The marketing mix (using the 7 Ps of marketing) ${ }^{7}$ matches the best combination of product, price, promotion, place, people, process and presence. In PREPP this takes the form of a menu of service options (infrastructure, management and tariff/payment) based on reliable knowledge of consumer preferences and coping strategies along with an assessment of what the utility can realistically provide.

Getting the mix right is crucial. For example, the introduction of communal stand posts with shared management (product) will not work without good communication to negotiate management arrangements (people). Similarly, the decentralisation of customer services to neighbourhood offices will not be effective without letting residents know about the move and office opening hours (promotion). Consideration of process is also important: the service provider needs to assess current demand and predict how demand will increase as per capita consumption and the customer base grow. Skills in community development are clearly needed to understand consumers' perspectives but such knowledge is only useful if services can be worked out to satisfy demand.

Marketing provides a framework for utility service improvement to which demand assessment approaches such as PREPP can contribute. ${ }^{3}$ The practice of designing service levels to suit particular customer groups may result in low-income households receiving less water per head than those better off. However, it can also make it possible to provide services to poor households that are financially sustainable for both providers and users. In this way it can advance both social inclusion and equity so providing 'some for all'.

\section{I. The customer value chain}

The customer value chain (to know, then target, sell and thereafter service customers) is used to develop and sustain a
Know your customer

Know-Target-Sell-Service

- Know who the existing and potential customer groups are

- Know their behaviours, attitudes, practices, perceptions and preferences

- Know their water use and buying habits

Target your customer

- Target specific customer groups (differentiated by housing type and density, for example)

- Target each with appropriate service, payment and management options (for example house connections, yard taps and water kiosks with or without storage tanks; payment at local offices, pay as you go, pre-paid tokens, etc.)

- Target at appropriate price levels

Sell to your customer

- Sell different service options using suitable promotion techniques

- Sell only after careful research and planning

- Sell at the right price

Note: consumer groups who use alternatives to the public water supply, have unauthorised piped connections or who currently receive free water may require specific and sensitive targeting.

Service your customer

- Service by providing a consistent standard

- Service through a balance of people, process and technology using knowledgeable staff

This demands a commitment to continual operational and managerial improvement, particularly in relation to internal communication and collaboration (for example between customer relations, billing, operation and maintenance and finance departments).

Table I. The customer value chain

productive relationship between a company (here a water utility) and its customers (the urban poor) ${ }^{8}$ (see Table 1). Breaking the chain obviously weakens the relationship, as seen in the case of the 'water utility-urban poor' relationship when the reasons for reduced willingness to pay go unchecked resulting in a loss of revenue and service deterioration.

\subsection{Knowing the urban poor}

An understanding of the circumstances of both rich and poor households can reveal the conditions that must be met in order for the service provider to retain existing customers and secure new ones, as well as opportunities to improve service levels and increase revenue.

Service providers tend to make assumptions about customersespecially the poor-without consulting them. It is commonly assumed, for example, that poor consumers cannot pay and as a result these people have to suffer wholly inadequate services. In fact, many poor communities already pay very high prices for water both in terms of direct costs (bills, payments to water vendors, etc.) and indirect costs (time spent collecting and transporting water, costs of poor health). One study in Kampala, Uganda found that consumers in low-income settlements who were not direct customers of the utility paid between three and seven times more for their water than those who were. ${ }^{9}$

Where the water supply to a city is generally inadequate, both rich and poor people have developed coping strategies. Studies of these strategies ${ }^{10}$ reveal how far (in terms of effort and cost) people will go in order to obtain water and the reasons why 
some customers abandon the public supply in favour of alternative sources. Triggers for reverting to non-utility supplies commonly include issues of reliability, convenience, perceived water quality, access (queuing times and availability) and faith in the existing supplier, local disputes and cultural beliefs and practices.

There is no blueprint for effective community consultation, but it is generally advisable to follow a step-by-step process that involves gauging the situation (understanding where the consumer is now), listening to the consumer (understanding where he/she wants to be), presenting realistic options and inviting feedback, then refining what is to be offered.

\subsection{Targeting and selling to the urban poor}

The 'urban poor' are hugely diverse in terms of socio-economic characteristics and geographical spread. Increasingly city authorities are unable to say where low-income/high housing density areas (where the poor traditionally reside) begin and end; in many cities low- and higher-income households are intermingled. Obtaining reliable data is important if utilities are to benefit from targeting segments of their market or prioritising limited resources. Experience is growing in the use of maps and GIS, as seen in Durban, South Africa and Tanzania. ${ }^{10}$ An alternative is to use proxies for income, for example, electricity connections or roof types.

\subsection{Providing choice}

Simply asking a poor community what they want can be counter-productive as it creates unrealistic expectations and fails to generate a sense of ownership and responsibility for services. This can then lead to disillusionment when expectations are not fulfilled. In order to make informed choices, community groups generally need technical support, including information on the different options that could actually be provided and the cost to be charged. Skilled external facilitators can help to ensure that everyone has a voice and the time to digest ideas before making a decision. Some common urban water service, management and payment options are described in Table 2.

\section{PREPP: ONE ‘DOABLE’ SOLUTION}

PREPP is based on a minimum framework that can be adapted. Conducted in focus groups segregated by gender, PREPP takes account of the different roles and perspectives of women and men in relation to water. Women generally carry water and determine coping strategies in times of shortage. Men are invariably the head of household and as such make purchase decisions.

Deciding the sample of women and men to include is not based on usual mathematical techniques. This is because PREPP sessions take place in the community and are likely to be set up through an intermediary, for example a community leader and his/her choice is unlikely to be a deliberate random sample. This is deemed satisfactory as PREPP is looking for trends and common preferences rather than precise measures. The rule is to apply common sense and sensitivity (Fig. 1).

PREPP takes participants through a set of carefully prepared steps in which a number of potential service options are compared with

\section{Service options}

- Individual house connections with various pressure regimes and frequency of water supply. Water is usually obtained from a tap in the house

- Individual yard connections at various pressure regimes and frequency of supply, where water is obtained from a tap outside the house. The house may not have internal plumbing

- Shared (yard) connections at various pressure regimes and frequency of supply (with a few households sharing one connection)

- Stand posts communal/public points where many people collect water. Stand posts are usually without an attendant and water is usually provided for free (particularly in South Asia)

- Water kiosks communal/public water points, technically similar to 'stand posts' where people buy water from a person who sells it from the kiosk. A utility, private operator or community group may manage the water kiosk and sell water at a predetermined price per container

- Supply by vendors using various modes of transport such as bicycles, hand carts, animal-pulled carts and motorised delivery vehicles (trucks) to deliver water to consumers

- Supply by water tankers by the utility or a private provider especially in cases of water shortages

\section{Management options}

- Utility managed (e.g. contracted tap attendants, kiosk operators)

- Shared management (e.g. community committees or community-contracted tap attendants manage water points and charge individual users at the point of collection; the revenue is used to pay the public service provider for the bulk supply)

- On-selling (e.g. household connection where the house owner pays the utility water bills but takes revenue from sales of water to neighbours)

- Privately managed kiosk (e.g. small water enterprises)

- Community management (e.g. hand pumps)

Payment options

- Pay as you go (e.g. pay by the bucket at a water point)

- Pre-paid (e.g. tokens)

- Billing (to individuals or groups; payment can sometimes be made in lump sums or instalments; at local or central offices; or to a visiting collector)

Table 2. Common service, management and payment options

those currently used. The key steps are shown in Table 3. The purpose of steps 1 to 3 is to learn about water use, including coping strategies and water services, including the utility from the perspective of the urban poor. Step 4 identifies service options that should be considered by the utility for future marketing in similar market segments. The main participatory tools used in PREPP are summarised below.

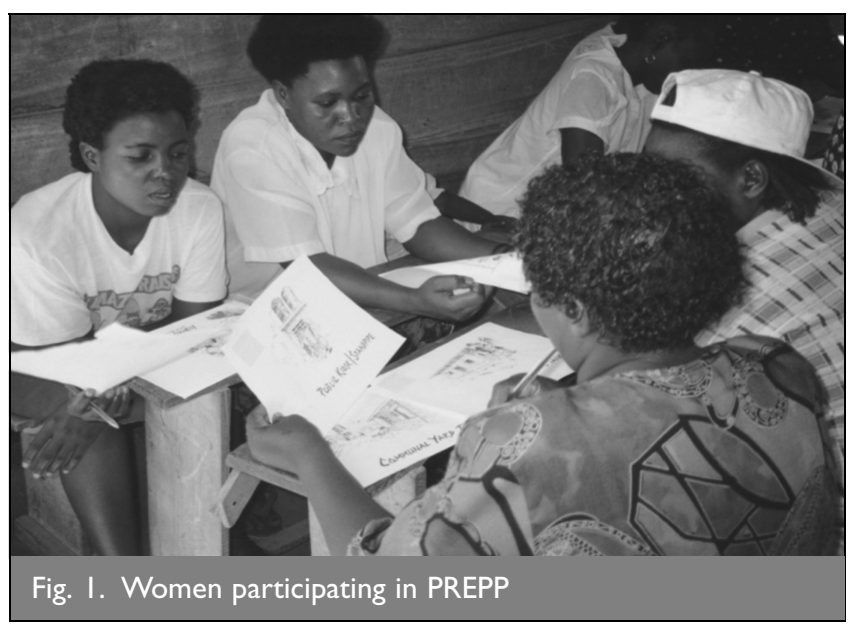




\begin{tabular}{lll}
\hline Step 1 & Existing experiences (sources, supply and coping strategies) & Water ladder and group probing \\
Step 2 & Existing preferences & Household voting, focus group probing and discussion \\
Step 3 & Consumer perceptions (of the utility) & Questions and probing \\
Step 4 & Service option preferences (existing options compared to new) & Costed option ranking Voting \\
Table 3. PREPP—-the basic steps & \\
\hline
\end{tabular}

\section{I. The water ladder}

The water ladder is a set of pictures (typically six to ten), each depicting a different water point or level of service. Presented in random order and with minimal explanation, the group is asked to sort the drawings according to their perceived merit, from 'poor' to 'acceptable' to 'good.' The ranked pictures create a 'ladder' with the least desirable option at the bottom. This can be done either to assess perceptions of existing water sources or to prioritise options for new or improved services.

The set of pictures used should reflect the range of water points that are actually found in the locality and hence some degree of local research is required in advance. It follows that a set of pictures prepared for use in one city might not be right for another. Figure 2 shows a ladder of existing water sources developed in Kampala, Uganda.

\subsection{Costed option ranking}

Costed Option Ranking (COR) determines consumer preferences for different water service options using cost-benefit analysis. COR is based on the water ladder but depicts utility-proposed service options. The facilitator presents the pictures one by one, in each case explaining what the option is, the level of service it that provides and the cost implications for consumers* (which might include both connection and consumption charges). These options are then compared and discussed with the help of the pictures, and the group finally ranks and votes in order of preference.

A sample of COR used in Kampala is shown in Figs 3 and 4. Note that in some cases more than one illustration is used for a single option to convey the processes involved (for example water vending).

\subsection{Facilitation and duration}

A team, typically one engineer, two social scientists or community development workers and a local artist, facilitates PREPP. The engineer is responsible for the presentation of technology and management options, and for explaining the form these service options may take, including the predicted cost. The social scientist or community development worker is responsible for managing the whole process, facilitating the discussion and interpreting the results. The local artist is useful for on-the-spot material or option development and refining existing pictures.

*The quoted prices for a unit of water (typically 20 litres) given during the exercise should be based on the expected water tariff and connection charge (where relevant) that is likely to be charged over the next couple of years.
During a PREPP focus group the facilitator uses a prepared list of questions and topic areas to make efficient use of the time, maintain the focus of the discussion and to enable the responses to be recorded systematically. He/she also 'probes' the group to explore critical problems in depth and ensures clarification is provided where necessary.

The use of probes also helps to elicit views about how the urban poor perceive the utility, its performance, reputation and who it is there for. This information is important in a climate where utilities are increasingly thinking 'customer first'.

Time is in short supply for utility staff. PREPP compared to other participatory appraisal methods is doable, provides sufficient information to enable the utility to plan from an informed position and is therefore more attractive. Obviously, further consultation will be required once projects are being implemented, for example deciding upon the location of pipes. An indicative time requirement for the whole process is given in Table 4.

\section{FIELD TEST FINDINGS}

The PREPP approach has been field tested in Uganda, Kenya, Zambia and India. In general terms the results revealed a good correlation between PREPP findings and data obtained via techniques that rely on a greater number of interviews, such as household semi-structured interviews and willingness-to-pay (WTP) surveys. ${ }^{3}$ Willingness-to-pay surveys may be used in conjunction for developing investment projections and guiding future water tariff policies.

The results from the PREPP COR in Mombasa, Kenya are a good example of the dangers of assuming demand. Respondents said they would prefer to use water kiosks, where they have to pay a high price per jerri-can of water, compared to using shared yard connections with neighbours, which would be cheaper. Probes into the reasons for their choices revealed concern about buying water from neighbours, which the respondents saw as a potential conflict situation. Further questioning revealed that conflict and security problems were already matters of wider community concern.

This situation contrasted with the results from Soroti in Uganda where yard connections and on-selling to neighbours was the most popular option (see Table 5). In Soroti the communities are more cohesive, less transitory and hence more willing to buy and sell water to neighbours.

\section{I. Comparisons with other methods}

In Guntor in India, PREPP focus groups and WTP surveys were carried out as part of a marketing study of water services. 

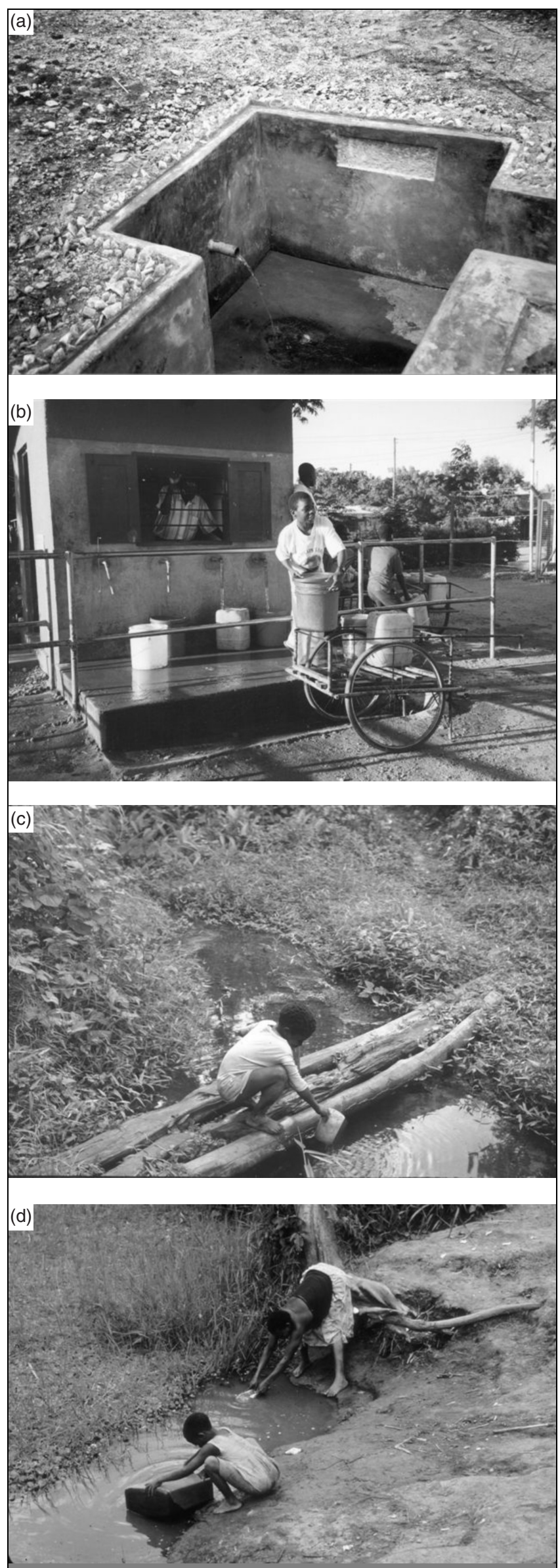

Fig. 2. (a) Shallow well; (b) paying for water; (c) bend and fetch; (d) protected spring ((a) and (c) courtesy of John Pickford, (b) courtesy of Cyrus Njiru, (d) courtesy of Brian Reed, all WEDC, Loughborough University, UK)
The WTP survey revealed that $52 \%$ of people living in informal settlements with existing piped supply, preferred to have individual connections even when the daily supply would be only for two hours. The second choice was group or shared connections (31\%). Four other service options were also offered. ${ }^{10}$ Costed option ranking results in seven informal settlements in Guntor revealed that individual connections were the most popular choice for men and group connections were generally preferred by women. The municipality could confidently offer both options in these settlements as part of any service improvement programmes.

Similarly, in Bushenyi in Uganda, PREPP and WTP surveys ${ }^{12}$ were conducted. Both sets of results revealed that yard connections were the most popular option in the central core areas of the town and protected springs were preferred in the fringe areas. In Kampala the PREPP results were compared with the outcome of semi-structured interviews with 99 respondents. ${ }^{9}$ Both sets of results revealed that the preferred option was individual ground tanks with piped supply and the second favourite option was public water kiosks. There was a discrepancy on the third preference, but further focus groups would be recommended where substantial service improvement programmes are planned.

During field testing it became clear that consumers are acutely aware of the costs, financial and otherwise, incurred in coping with existing water supply options and are open to discussion about how these compare with the proposed unit and management costs of improved service options. They are also able to explain their preferences for particular service levels in some detail, including management and payment options. Alternative approaches rarely feed such information to engineers first hand.

\section{USING THE FINDINGS}

PREPP combines quantitative and qualitative data and this is the real value of the process, particularly in respect of insights into coping strategies, willingness to pay and attitudes. It is important, however, to verify the results, for example by: observing the use of local water sources; conducting a minimum of two PREPP sessions in each residential area (more in large communities) and comparing findings; cross-checking results with other available data such as household consumer surveys; and revisiting the research areas to verify the results with community groups.

When a number of PREPP sessions have been conducted throughout an urban area, average ranking values for all results can be included in summary tables. Because a utility would generally be looking for around three or four service options to promote, it does not matter if some areas have slightly different ranking orders compared to other areas where PREPP sessions have been conducted. If, however, there are large discrepancies between the preferred options between two low-income areas, the results should be checked, perhaps with further surveys. If large discrepancies are confirmed, then the utility should consider offering different options in different informal settlements, or reach some compromise menu of options to be offered. 


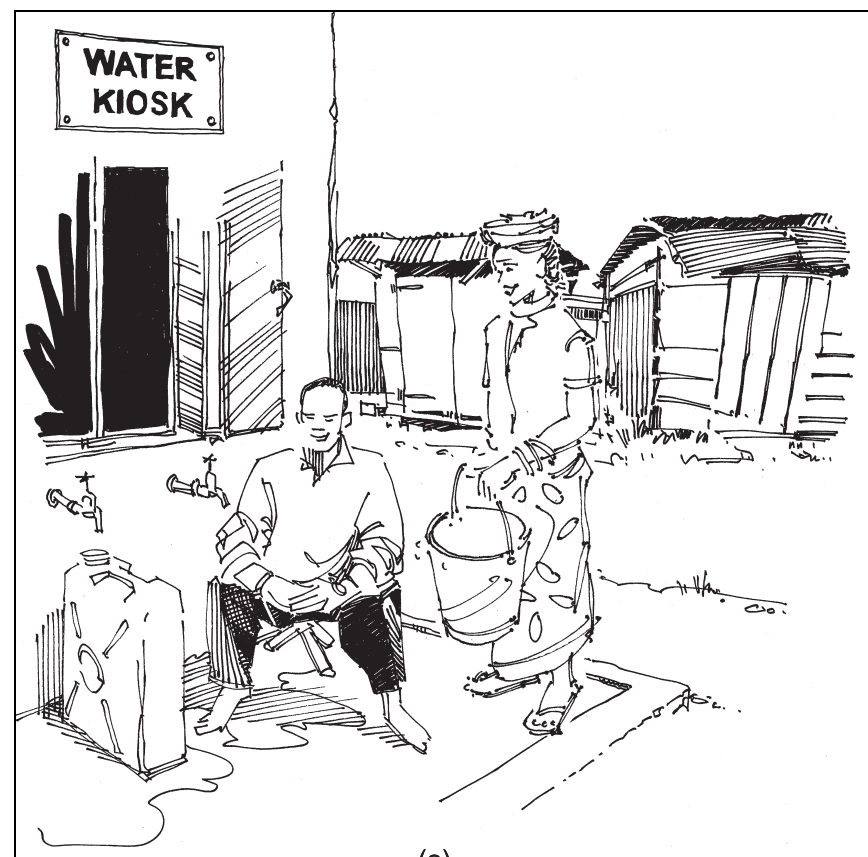

(a)

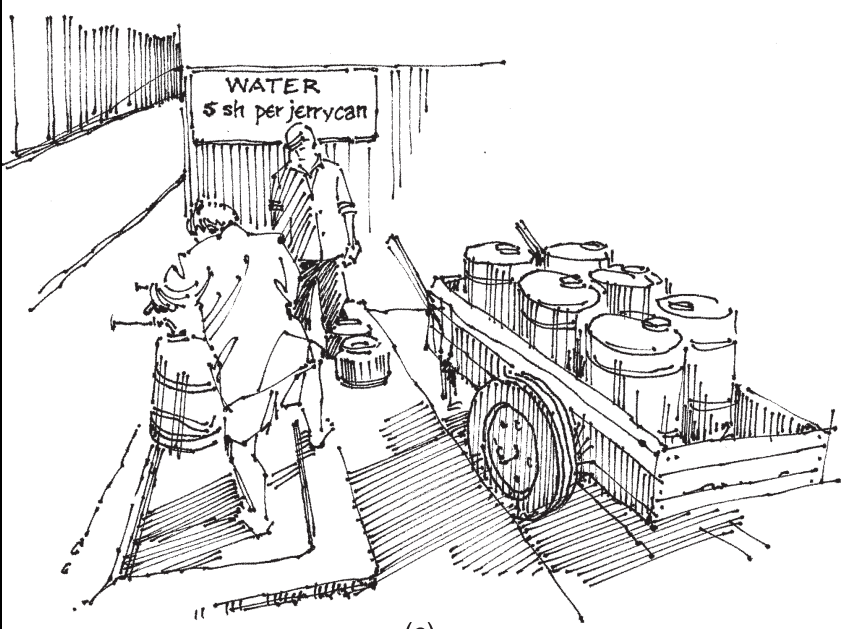

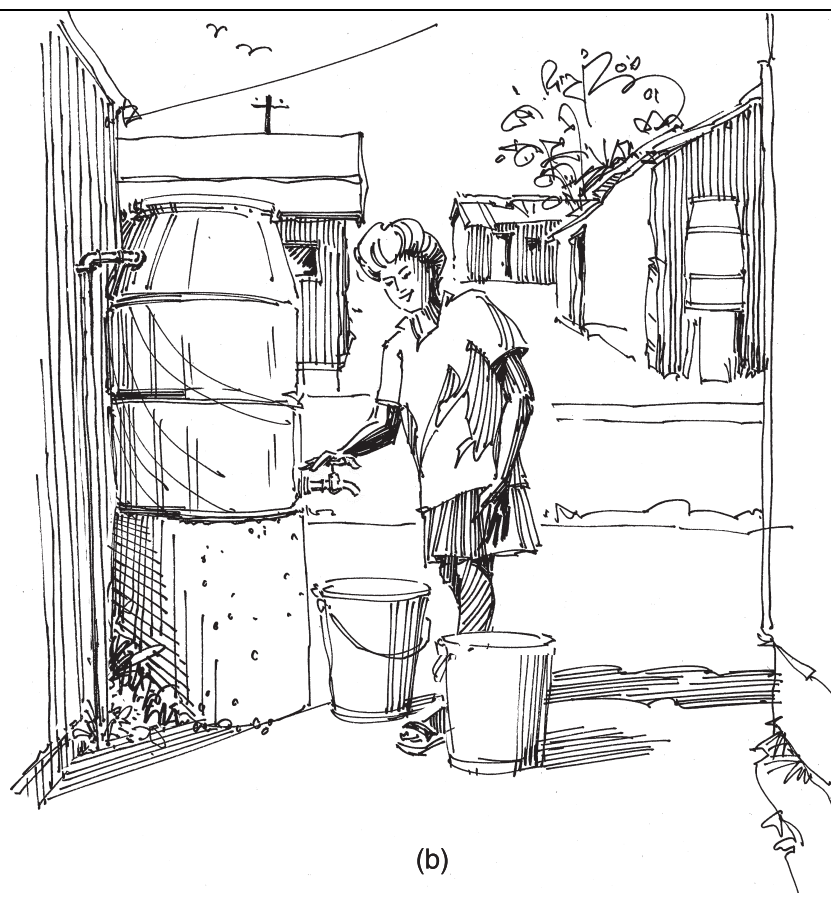
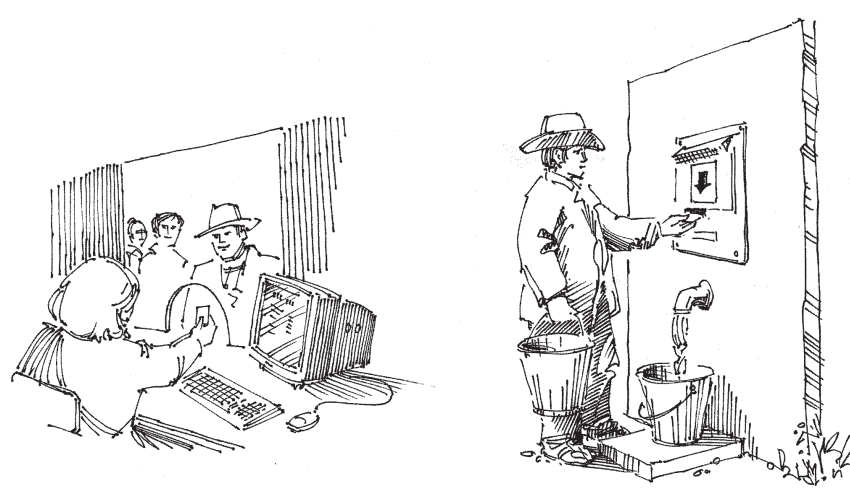

(d)

Fig. 3. Examples of drawings used for a costed option exercises in Kampala: (a) public kiosk; (b) individual tank; (c) water vendor; (d) smart token

\section{CONCLUDING COMMENTS}

While PREPP can give an indication of consumers' willingness to pay it will not reveal the maximum amount that people are willing to pay, which is useful in developing tariff structures. This can best be determined via comprehensive WTP surveys.

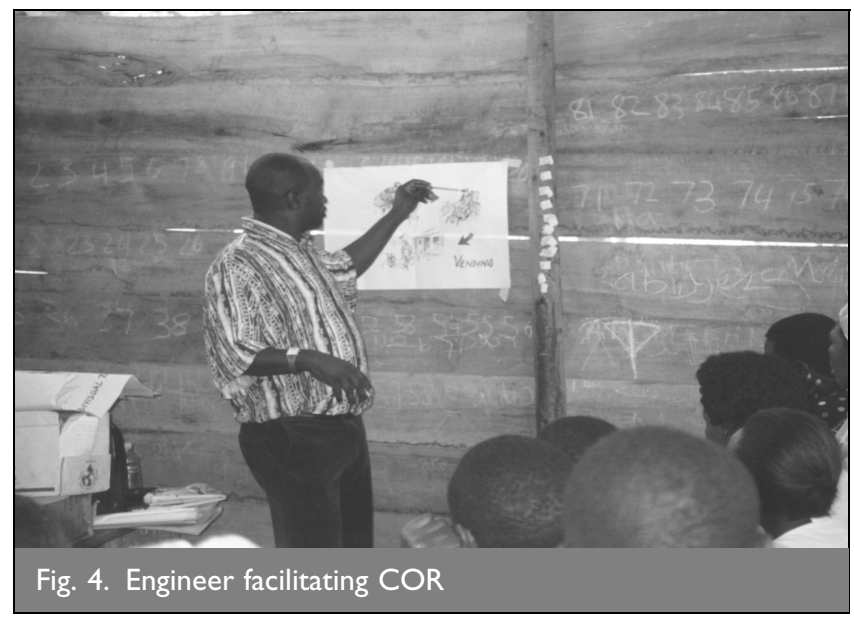

PREPP offers a relatively rapid (and thus attractive) participatory approach that is adaptable to different situations. It provides valuable insights into water service perceptions, preferences and coping strategies of people living in informal settlements. The COR component provides good information on people's preferences for proposed service options, which is valuable for

\begin{tabular}{|c|c|}
\hline Time & Activity \\
\hline Up to 5 days & $\begin{array}{l}\text { Arranging for the production of } \\
\text { pictures, liaison with the identified } \\
\text { community and team orientation }\end{array}$ \\
\hline $\begin{array}{l}\text { Up to I day per PREPP } \\
\text { session (one session } \\
\text { equals I male and } \\
\text { | female group) }\end{array}$ & $\begin{array}{l}\text { Although a session only takes two } \\
\text { hours, time is required for logistics } \\
\text { and the writing up of the results }\end{array}$ \\
\hline 3 to 5 days & $\begin{array}{l}\text { At the end of the session schedule } \\
\text { to analyse, report and present } \\
\text { the findings }\end{array}$ \\
\hline
\end{tabular}




\begin{tabular}{|c|c|c|c|c|c|c|}
\hline \multirow[b]{2}{*}{ Option } & \multicolumn{2}{|c|}{ First choice } & \multicolumn{2}{|c|}{$\begin{array}{l}\text { Second } \\
\text { choice }\end{array}$} & \multicolumn{2}{|c|}{ Third choice } \\
\hline & Core* & Fringe & Core & Fringe & Core & Fringe \\
\hline Protected spring & । & | & I & 5 & 2 & 5 \\
\hline Borehole & 0 & 2 & | | & 5 & 4 & 10 \\
\hline Kiosk & 0 & 3 & 2 & 3 & 7 & 3 \\
\hline Yard connection & 16 & 14 & 0 & 3 & I & 5 \\
\hline House connection & 1 & 1 & 3 & 2 & 0 & 0 \\
\hline Vendor & 0 & 0 & I & 0 & 4 & 0 \\
\hline
\end{tabular}

*The core areas refer to the centre of the town and 'fringe' refers to the less dense areas on the edge of the town. (Source: Oriono et al. ${ }^{14}$ )

Table 5. PREPP voting for water supply options in Soroti, Uganda

predicting demand and the uptake of options as part of new water investment programmes. Utilities can thus be more confident of getting a better return on their investment compared with the old 'assume demand and provide' approach. It also provides an invaluable on-the-job training tool for practising engineers.

Above all, PREPP breaks a mould. By teaming engineers and sociologists, professionals jointly engage rather than be merely consulted. Assumptions are challenged and common goals are identified. This has to be good for sustainable infrastructure development and for making sure the house does indeed have a door and, better still, one of the right colour.

\section{I. ACKNOWLEDGEMENTS}

The authors acknowledge the work of Dr Sam Kayaga (WEDC), Dr Richard Franceys (Cranfield University, Silsoe), Srinivas Chary and Sri. A. Narender (Administrative Staff College, India), Dr Cyrus Njiru (WEDC) and all the field workers and utility staff in Uganda, Kenya, Zambia and India who collaborated with this research. The Department for International Development (DFID) as part of their Knowledge and Research programme supported the research that informs this paper. However, the views expressed are those of the authors and not necessarily those of DFID. Further guidance on the approaches discussed is provided in Book 3: PREPP-Utility Consultation with the Urban Poor. ${ }^{13}$

\section{REFERENCES}

1. WHO/UNICEF. Meeting the Millennium Development Goal Drinking-water and Sanitation Target; A Mid-term Assessment of Progress. Joint Monitoring Programme,
World Health Organization and United Nations Children's Fund, 2004.

2. Batley R. A. and Larbi G. The Changing Role of Government-The Reform of Public Services in Developing Countries. Macmillan, Palgrave, 2004.

3. Sansom K. R., Franceys R., Nuiru C., Coates S. and KaYAga S. Serving All Urban Consumers-A Marketing Approach to Water Services in Low and Middle Income Countries, Book 2: Guidance Notes for Managers. WEDC, Loughborough University, 2004.

4. REED B. J. (ed.) Infrastructure For All. WEDC, Loughborough University, 2005.

5. Deverill P., Bibby S., Wedgwood A. and Smout I. K. Designing Water Supply and Sanitation Projects to Meet Demand in Rural and Urban Communities, Book 1: Concept, Principles and Practices. WEDC, Loughborough University, 2002.

6. Jones P. (ed.) Management in Service Industries. Pitman Longman, London, 1989.

7. Brassington F. and Pettitt S. Principles of Marketing, 2nd edn. Financial Times/Prentice Hall, London, 2000.

8. SAGE R. Meaningful Relations. Water Services, Xxxxxxxxxxx, 2002.

9. Kayaga S. M. and Sansom K. R. Serving All Urban Consumers-A Marketing Approach to Water Services in Low and Middle Income Countries, Book 5: Sample Strategic Marketing Plan for Water Services in Kampala City. WEDC, Loughborough University, 2004.

10. Narender A., Chary S. and Sansom K. R. Serving All Urban Consumers-A Marketing Approach to Water Services in Low and Middle Income Countries, Book 6: Sample Strategic Marketing Plan for Water Services in Guntor India. WEDC, Loughborough University, 2004.

11. Banda A. C., Coates S., Mbawo E. and Nyumbu I. L. Services to Low Income Consumers, Report 3: Low Income Consumer Survey. Peri-urban Section, Lusaka Water and Sewerage Company and Water Utilities Partnership (Africa), 2003.

12. Wedghood A. and Sansom K. R. Willingness to Pay Surveys-A Streamlined Approach. Guidance Notes for Small Town Water Services. WEDC, Loughborough University, 2003.

13. Coates S., Sansom K. R., Kayaga S. M., Chary S., NARENDER A. and NJiRu C. Serving All Urban Consumers: A Marketing Approach to Water Services in Low and Middle Income Countries, Book 3: PREPP-Utility Consultation with the Urban Poor. WEDC, Loughborough University, 2004.

14. Eyatu Oriono 0. J., Sewanyana S. and Kazibwe E. The Use of the PREPP Methodology with Communities in Uganda Small Towns. A Case Study of Bushenyi and Soroti. WEDC, Loughborough University, 2001 (unpublished).

\section{What do you think?}

To comment on this paper, please email up to 500 words to the editor at journals@ice.org.uk

Proceedings journals rely entirely on contributions sent in by civil engineers and related professionals, academics and students. Papers should be $2000-5000$ words long, with adequate illustrations and references. Please visit www.thomastelford.com/journals for author guidelines and further details. 